Available online: https://ejurnalunsam.id/index.php/jagris

\title{
Pengaruh Sistem Tanam, Biaya Pemupukan dan Biaya Pestisida Terhadap Pendapatan Usahatani Padi Sawah di Kecamatan Birem Bayeun Kab. Aceh Timur
}

\author{
M. Sareza ${ }^{1}$, Hanisah ${ }^{2}$, Rozalina ${ }^{3}$ \\ 1,2,3,4 Prodi Agribisnis Fakultas Pertanian Universitas Samudra, Indonesia. \\ *Corresponding author's e-mail: hanisah@unsam.ac.id
}

\begin{abstract}
ABSTRAK
Tujuan penelitian untuk mengetahui sistem tanam, biaya pemupukan dan biaya pestisida berpengaruh terhadap pendapatan usahatani padi sawah di Kecamatan Birem Bayeun Kabupaten Aceh Timur. Penelitian ini dilakukan dengan menggunakan metode survei. Jumlah petani sampel dalam penelitian ini yang diambil sebanyak $20 \%$ dari jumlah populasi. sebanyak 150 orang dan petani sampel pada masing-masing desa yaitu 30 orang. Metode analisis yang digunakan yaitu regresi linier berganda. Hasil penelitian Secara parsial variabel sistem tanam dan biaya pestisida tidak berpengaruh terhadap pendapatan usahatani padi sawah di Kecamatan Birem Bayeun. Sedangkan variabel biaya pemupukan berpengaruh sangat nyata terhadap pendapatan usahatani padi di Kecamatan Birem Bayeun.
\end{abstract}

Kata Kunci:

padi; pupuk; pestisida; pendapatan; sistem tanam

\begin{abstract}
The aim of this research to know plant system, fertilizer cost, pesticide cost effected to revenue of paddy farm business Birem Bayeun sub-district East Aceh district. This research used survey method. Farmer sample in this research was 20\% from a 150 person population and the sample was 30 farmer from each village. the analysis method used multiple linear regression. Result showed that plant system and pesticide cost weren't effected. Meanwhile fertilizer cost was effected to revenue of paddy farm business in Birem Bayeun sub-district.
\end{abstract}

Keyword:

paddy, fertilizer; pesticide; revenue; plant system

How to Cite: Sareza, M., Hanisah., Rozaliana. (2019). Pengaruh Sistem Tanam, Biaya Pemupukan dan Biaya Pestisida Terhadap Pendapatan Usahatani Padi Sawah di Kecamatan Birem Bayeun Kab. Aceh Timur. Jurnal Penelitian Agrisamudra. 6(1): 30-38 


\section{Pendahuluan}

Pembangunan nasional serta tidak lepas dari fungsinya sebagai sumber utama ketahanan pangan. Dalam meningkatkan ketahanan pangan, tantangan terbesar saat ini adalah konsumsi masih bertumpu pada beras. Segala upaya telah dilakukan dalam rangka peningkatan produksi pangan terutama beras yang masih terus menjadi masalah utama. Meskipun revolusi hijau di bidang produksi telah berhasil mengejar tingginya pertumbuhan penduduk, namun masih belum dapat mengubah ketergantungan masyarakat terhadap beras.

Padi merupakan salah satu produk pertanian yang utama, karena mengingat bahwa sebagian besar penduduk Indonesia mengkonsumsi beras sebagai komoditas utama. Maka dalam hal ini perlunya pengembangan usahatani yang dilakukan oleh pemerintah guna menjadikan negara Indonsia sebagai negara swasembada pangan, khususnya komoditas padi. Luas usahatani padi di Kecamatan Birem Bayeun tahun 2016 yaitu 765 Ha dengan produksi 3.842 ton dan rata-rata produktivitas 5,07 ton/ha. Lahan terluas terdapat di Desa Buket Lhee yaitu 210 hektar dengan produksi 1050 ton dan produktivitas 5,00 ton/ha, sedangkan lahan terkecil terdapat di Desa Alue Canang seluas 2 hektar dengan produksi 11 ton dan produktivitas 5,50 ton/ha.

Sistem tanam adalah suatu upaya untuk meningkatkan produksi gabah tanaman padi sawah. Ada beberapa jenis sistem tanam yang umum digunakan petani yaitu: sistem tanam jajar legowo, sistem tanam tegal, sistem tanam benih langsung (tabela) dan sistem tanam lainnya. Sistem tanam legowo adalah suatu rekayasa teknologi untuk mendapatkan populasi tanaman lebih dari 160.000 perhektar. Penerapan Jajar Legowo selain meningkatkan populasi pertanaman, juga mampu menambah kelancaran sirkulasi sinar matahari dan udara di sekeliling tanaman pinggir sehingga tanaman dapat berfotosintesis lebih baik. Sistem tanam legowo 4:1 merupakan pola tanam legowo dengan keseluruhan baris mendapat tanaman sisipan. Pola ini cocok diterapkan pada kondisi lahan yang kurang subur.

Dengan pola ini, populasi tanaman mencapai 256.000 rumpun/ha dengan peningkatan populasi sebesar $60 \%$ dibanding pola tegel $(25 \times 25 \mathrm{Cm})$. Teknologi sistem tanam modern belum sepenuhnya diterima oleh para petani, petani menganggap sistem tanam yang mereka pakai sejak dahulu sudah benar. Oleh karena itu perlu adanya sosialisasi tentang sistem tanam modern. Sistem tanam yang bervariasi di daerah penelitian, membuat biaya yang digunakan dalam melakukan kegiatan penanaman padi sawah berbedabeda, hal tergantung tingkat kemampuan petani dalam usahatani padi sawah.

Pupuk adalah zat atau bahan makanan yang diberikan kepada tanaman dengan maksud agar zat tersebut dapat diserap oleh tanaman. Pupuk merupakan zat yang berisi satu atau lebih nutrisi yang digunakan untuk mengembalikan unsur-unsur yang habis terhisap tanaman dari tanah. Dalam pemberian pupuk harus dengan dosis yang tepat serta waktu yang tepat pula agar keseimbangan zat mineral dapat dipertahankan sehingga dapat meningkatkan hasil produksi pertanian. Biaya pemupukan termasuk ke 
dalam biaya variabel, agar efektif dan efisien, penggunaan pupuk disesuaikan dengan kebutuhan tanaman dan ketersediaan hara dalam tanah. Di daerah penelitian penggunaan pupuk bervariasi, sehingga biaya pemupukan atau biaya untuk membeli pupuk berbeda-beda tergantung kemampuan petani dalam menggunakan biaya pemupukan.

Pestisida adalah substansi kimia yang digunakan untuk membunuh atau mengendalikan berbagai hama dan penyakit tanaman. Dalam pemakaian pestisida harus memperhatikan dosis maupun ukurannya. Pestisida pada hakikatnya merupakan racun apabila pemakaiannya terlalu banyak akan bersifat merugikan. Petani menggunakan pestisida untuk membantu program intensifikasi dalam rangka mengatasi masalah hama dan penyakit menyerang tanaman pertanian. Pestisida dapat secara cepat menurunkan populasi hama yang menyerang tanaman sehingga penurunan hasil pertanian dapat dikurangi. Namun sebagian petani belum mengetahui dan tidak mempedulikan prosedur penggunaan pestisida sehingga membuat hama menjadi kebal dan bisa membahayakan petani dalam pengaplikasiannya. Penggunaan pestisida di daerah penelitian bervariasi, sehingga biaya penggunaan pestisida berbedabeda, bergantung kemampuan petani dalam penggunaan biaya pestisida.

Tujuan utama dijalankan suatu usahatani adalah untuk memperoleh pendapatan. Dimana pendapatan tersebut dapat digunakan untuk memenuhi kebutuhan hidup dan kelangsungan hidup usahanya. Pendapatan yang diterima dalam bentuk uang. Dimana uang merupakan alat pembayaran atau alat penukar. Pendapatan yang didapat petani merupakan faktor pemicu yang sekaligus pendorong untuk terus berusahatani padi sawah dalam rangka memenuhi kebutuhan keluarga petani dan untuk biaya produksi berikutnya. Berdasarkan keseluruhan masalah diatas maka penulis tertarik untuk membahas dan mencoba melakukan penelitian dengan judul Pengaruh sistem tanam, biaya pemupukan, dan biaya pestisida terhadap pendapatan usahatani padi sawah di Kecamatan Birem Bayeun Kabupaten Aceh Timur.

\section{Metode Penelitian}

Objek pada penelitian ini adalah petani yang berusahatani padi sawah di Kecamatan Birem Bayeun. Ruang lingkup penelitian ini dibatasi pada pengaruh sistem tanam, biaya pemupukan dan biaya pestisida terhadap pendapatan usahatani padi sawah di Kecamatan Birem Bayeun Kabupaten Aceh Timur. Kecamatan Birem Bayeun terdapat 27 desa, dari 27 desa tersebut yang memiliki usahatani padi berjumlah 17 desa. Dalam penelitian ini dari 17 desa tersebut dipilih 4 desa sampel secara "purposive sampling" yaitu : Desa Buket Lhee, Desa Paya Bili Sa, Desa Merbau Dua dan Desa Jambo Labu dengan pertimbangan ke 4 desa tersebut memiliki luas lahan dan produksi padi tertinggi dibandingkan desa yang lain.

Pengambilan petani sampel dilakukan dengan menggunakan metode Simple Random Sampling (teknik pengambilan secara acak). Wiratha (2006:238) mengemukakan dalam sampel random sederhana, anggota populasi tidak dipilah-pilah atau distratakan 
terlebih dahulu. Semua anggota populasi langsung dipilih secara random (acak). Jumlah petani sampel dalam penelitian ini yang diambil adalah sebanyak $20 \%$ dari populasi petani tiap-tiap desa sampel.

Tabel 1. Jumlah Populasi dan Sampel

\begin{tabular}{lccc}
\hline No & Desa Sampel & $\begin{array}{c}\text { Jumlah Populasi } \\
\text { (Orang) }\end{array}$ & $\begin{array}{c}\text { Jumlah Sampel } \\
\text { (Orang) }\end{array}$ \\
\hline 1 & Buket Lhee & 55 & 11 \\
2 & Paya Bili Sa & 42 & 8 \\
3 & Merbau Dua & 29 & 6 \\
4 & Jambo Labu & 24 & 5 \\
\hline & Jumlah & 150 & 30 \\
\hline
\end{tabular}

Sumber: Data Primer (2018)

Dari tabel 1. di atas dapat dilihat bahwa jumlah populasi dalam penelitian adalah sebanyak 150 orang. Jumlah sampel pada masing-masing desa yaitu Desa Buket Lhee 11 orang, Desa Paya Bili Sa 8 orang, Desa Merbau Dua 6 orang, dan Desa Jambo Labu 5 orang, sehingga jumlah sampel keseluruhan yaitu 30 orang

Analisis yang digunakan dalam penelitian ini adalah analisis regresi linear berganda, dengan satu variabel dependen $(Y)$ dan tiga variabel independen yaitu variabel $(X)$ dengan persamaan regresinya sebagai berikut :

$\mathrm{Y}=\mathrm{a}_{0}+\mathrm{a}_{1} \mathrm{X}_{1}+\mathrm{a}_{2} \mathrm{X}_{2}+\mathrm{a}_{3} \mathrm{X}_{3}+\mathrm{e}$

Keterangan :

$\mathrm{Y}=$ Pendapatan Petani $(\mathrm{Rp} / \mathrm{Ha} / \mathrm{MT})$

$\mathrm{X}_{1} \quad=$ Sistem tanam ( Skor )

$\mathrm{X}_{2} \quad=$ Biaya Pemupukan $(\mathrm{Rp} / \mathrm{Ha} / \mathrm{MT})$

$\mathrm{X}_{3} \quad=$ Biaya Pestisida $(\mathrm{Rp} / \mathrm{Ha} / \mathrm{MT})$

$\mathrm{a}_{0} \quad=$ Konstanta

$\mathrm{a}_{1,2,3} \quad=$ Parameter yang dicari

e $\quad=$ Error

untuk menilai sistem tanam dihitung dengan menggunakan Skor, sistem tanam legowo 4:1 dengan skor " 3 ", sistem tegel dengan skor " 2 " dan sistem tabela dengan skor " 1 ".

\section{Hasil dan Pembahasan}

\subsection{Karakteristik Usahatani}

\section{a. Luas lahan}

Luas lahan garapan yang di usahakan berbeda antara petani yang satu dengan petani yang lain. Untuk lebih jelasnya rata-rata luas lahan garapan usahatani padi yang dikelola petani sampel dapat dilihat pada tabel 2. Tabel 2 di bawah dapat dilihat bahwa rata-rata luas lahan usahatani padi yang dikelola oleh petani sampel adalah sebesar 0,65 hektar, dimana luas lahan lahan yang terbesar terdapat pada Desa Buket Lhee sebesar 0,81 hektar dan luas lahan padi yang terkecil terdapat pada Desa Jambo Labu yaitu sebesar 0,56 hektar. Luas lahan tanaman padi rata-rata seluas 0,65 hektar bukanlah luas lahan yang ideal untuk usahatani tanaman padi karena pendapatan yang diperoleh tidak mencukupi kebutuhan keluarga, sehingga dapat dikatakan petani padi di Kecamatan Birem Bayeun berusaha mencari tambahan pendapatan dari sector lain. 
Tabel 2. Luas Lahan

\begin{tabular}{lcc}
\hline No & Desa Sampel & Luas Lahan \\
\hline 1 & Buket Lhee & 0,81 \\
2 & Paya Bili Sa & 0,64 \\
3 & Merbau Dua & 0,60 \\
4 & Jambo Labu & 0,56 \\
\hline & Rata-rata & 0,65
\end{tabular}

Sumber: Data Primer (2018)

b. Tenaga Kerja

Penggunaan tenaga kerja pada usahatani padi sawah meliputi kegiatan pengolahan lahan, pembibitan, penanaman, pemeliharaan dan pemanenan. Dalam menghitung besarnya pencurahan tenaga kerja yang diserap untuk setiap fase kegiatan, seluruhnya dikonversikan ke dalam Hari Kerja Pria (HKP). Rata-rata penggunaan tenaga kerja usahatani padi sawah di Kecamatan Birem Bayeun dilihat pada tabel 3 berikut.

Tabel 3. Jumlah Tenaga Kerja

\begin{tabular}{|c|c|c|c|c|c|}
\hline \multirow{2}{*}{ No } & \multirow{2}{*}{ Desa Sampel } & \multicolumn{2}{|c|}{ Tenaga Kerja } & \multirow{2}{*}{$\begin{array}{c}\text { Jumlah TK } \\
\text { (HKP/MT/UT) }\end{array}$} & \multirow{2}{*}{$\begin{array}{c}\text { Jumlah TK } \\
\text { (HKP/MT/Ha }\end{array}$} \\
\hline & & DK/UT & LK/UT & & \\
\hline 1 & Buket Lhee & 32,8 & 38,49 & 71,29 & 94,3 \\
\hline 2 & Paya Bili Sa & 35,16 & 29,36 & 65,43 & 106 \\
\hline 3 & Merbau Dua & 27,93 & 33,63 & 61,57 & 105,65 \\
\hline \multirow[t]{2}{*}{4} & Jambo Labu & 36,62 & 23,24 & 59,68 & 117,35 \\
\hline & Jumlah & 33,13 & 31,18 & 64,31 & 105,83 \\
\hline
\end{tabular}

Sumber: Data Primer (2018)

Tabel 3. di atas dapat dilihat bahwa rata-rata pengunaan tenaga kerja usahatani padi di Kecamatan Birem Bayeun yaitu sebesar 64,31 HKP/MT/UT dan 105,83 HKP/MT/Ha. Rata-rata penggunaan tenaga kerja terbesar di Desa Buket Lhee sebesar 71,29 HKP/MT/UT dan terkecil di Desa Jambo Labu sebesar 59,86 HKP/MT/UT. Penggunaan tenaga kerja yang besar terhadap Desa Buket Lhee disebabkan lahan yang luas. Semakin besar luas lahan usahatani maka semakin besar tenaga kerja yang dibutuhkan.

\section{c. Biaya Produksi}

Rata-rata penggunaan biaya produksi perusahatani permusim tanam (perUT/MT) pada usahatani padi sawah di Kec. Birem Bayeun dapat dilihat pada tabel 4. berikut ini:

Tabel 4. Biaya Produksi

\begin{tabular}{|c|c|c|c|c|c|}
\hline \multirow[b]{2}{*}{ No } & \multirow[b]{2}{*}{ Desa Sampel } & \multicolumn{2}{|c|}{ Biaya } & \multirow{2}{*}{$\begin{array}{c}\text { Biaya } \\
\text { Produksi } \\
(\mathrm{Rp} / \mathrm{MT} / \mathrm{UT})\end{array}$} & \multirow{2}{*}{$\begin{array}{c}\text { Biaya } \\
\text { Produksi } \\
\text { (Rp/MT/Ha }\end{array}$} \\
\hline & & FC/UT & VC/UT & & \\
\hline 1 & Buket Lhee & 1.353 .182 & 6.460 .909 & 6.814 .091 & 8.892 .151 \\
\hline 2 & Paya Bili Sa & 1.082 .781 & 4.868 .625 & 5.951 .406 & 9.695 .375 \\
\hline 3 & Merbau Dua & 1.024 .875 & 4.541 .667 & 5.566 .542 & 9.534 .606 \\
\hline 4 & Jambo Labu & 958.700 & 4.377 .200 & 5.335 .900 & 10.218 .634 \\
\hline & Jumlah & 1.104 .885 & 4.938 .500 & 6.088 .167 & 9.455 .916 \\
\hline
\end{tabular}

Sumber: Data Primer (2018)

Tabel 4. di atas dapat dilihat rata-rata biaya produksi usahatani padi di Kecamatan Birem Bayeun yaitu sebesar Rp. 6.088.167 /MT/UT dan Rp 9.455.916 MT/Ha. Rata-rata 
penggunaan biaya produksi tertinggi berada di Desa Buket Lhee sebesar Rp. 6.814.091 /MT/UT, sedangkan biaya produksi terendah berada di Desa Jambo Labu sebesar Rp. 5.335.900 /MT/UT. Dalam penggunaan biaya produksi terdapat biaya tetap dan biaya variabel, biaya tetap terdapat penyusutan alat dan sewa lahan sedangkan biaya variabel terdapat pestisida, pupuk dan tenaga kerja.

\section{d. Produksi dan Pendapatan Bersih Usaha Tani}

Rata-rata produksi usahatani padi sawah di Kecamatan Birem Bayeun dapat dilihat pada tabel 5. berikut ini.

Tabel 5. Jumlah Populasi dan Sampel

\begin{tabular}{lccc}
\hline No & Desa Sampel & $\begin{array}{c}\text { Produksi } \\
\text { (Kg/MT/UT) }\end{array}$ & $\begin{array}{c}\text { Produksi } \\
\text { (Kg/MT/Ha) }\end{array}$ \\
\hline 1 & Buket Lhee & 3.973 & 4.887 \\
2 & Paya Bili Sa & 3.075 & 4.788 \\
3 & Merbau Dua & 3.133 & 5.259 \\
4 & Jambo Labu & 2.700 & 4.807 \\
\hline & Rata-rata & 3.220 & 4.935 \\
\hline
\end{tabular}

Sumber: Data Primer (2018)

Tabel 5. dapat dilihat bahwa rata-rata produksi usahatani padi petani sampel di Kecamatan Birem Bayeun yaitu sebesar $3.220 \mathrm{Kg} / \mathrm{MT} / \mathrm{UT}$ dan $4.935 \mathrm{Kg} / \mathrm{MT} / \mathrm{UT} / \mathrm{Ha}$. Rata-rata produksi tertinggi berada di Desa Buket Lhee yaitu sebesar $3.973 \mathrm{Kg} / \mathrm{MT} / \mathrm{UT}$ dan terkecil berada di Desa Jambo Labu sebesar $2.700 \mathrm{Kg} / \mathrm{MT} / \mathrm{UT}$. Produksi yang tinggi maupun rendah sangat dipengaruhi oleh berbagai faktor yaitu luas lahan, pemupukan dan perawatan. Pemupukan yang tidak sesuai dapat menghambat pertumbuhan dan memproduksi.

Pendapatan bersih sangat dipengaruhi oleh besarnya nilai produksi dan besarnya biaya produksi usahatani padi. Pendapatan bersih yaitu selisih antara nilai produksi dengan total biaya produksi. Rata-rata pendapatan bersih usahatani padi petani sampel di Kecamatan Birem Bayeun dapat dilihat pada tabel 6. berikut ini.

Tabel 5. Rata-rata Pendapatan Bersih Usaha Tani

\begin{tabular}{|c|c|c|c|c|c|}
\hline No & Desa Sampel & $\begin{array}{c}\text { Nilai } \\
\text { Produksi } \\
\text { (Rp/MT/UT) }\end{array}$ & $\begin{array}{c}\text { Biaya } \\
\text { Produksi } \\
(\mathrm{Rp} / \mathrm{MT} / \mathrm{UT})\end{array}$ & $\begin{array}{c}\text { Pendapatan } \\
\text { Bersih } \\
\text { (Rp/MT/UT) }\end{array}$ & $\begin{array}{c}\text { Pendapatan } \\
\text { Bersih } \\
\text { (Rp/MT/UT) }\end{array}$ \\
\hline 1 & Buket Lhee & 17.877 .273 & 6.814 .091 & 11.063 .182 & 13.098 .271 \\
\hline 2 & Paya Bili Sa & 13.837 .500 & 5.951 .406 & 7.886 .094 & 11.851 .723 \\
\hline 3 & Merbau Dua & 14.100 .000 & 5.566 .542 & 8.533 .458 & 14.129 .680 \\
\hline \multirow[t]{2}{*}{4} & Jambo Labu & 12.150 .000 & 5.335 .900 & 6.814 .100 & 11.411 .366 \\
\hline & Rata-rata & 14.491 .193 & 6.088 .167 & 9.001 .833 & 12.622 .760 \\
\hline
\end{tabular}

Sumber: Data Primer (2018)

Tabel 5. dapat dilihat bahwa rata-rata produksi usahatani padi petani sampel di Tabel V-7 di atas dapat dilihat bahwa rata-rata pendapatan bersih usahatani padi sawah di Kecamatan Birem Bayeun yaitu sebesar Rp. 9.001.833 /MT/UT dan Rp. 12.622.760 MT/Ha. Rata-rata pendapatan bersih usahatani padi tertinggi berada di Desa Buket Lhee yaitu sebesar Rp. 11.063.182, -/MT/UT. Sedangkan pendapatan bersih terkecil berada di Desa Jambo Labu sebesar Rp. 6.814.100,-/MT/UT. 


\subsection{Analisis regresi}

Sistem tanam pada usahatani padi sawah di Kecamatan Birem Bayeun dengan analisis kualitatif yang dikuantitatifkan berdasarkan skor jawaban petani sampel pada indikator yang disusun pada kuisioner penelitian. Hasil penelitian dalam bentuk jawaban atas kuisioner tentang pernyataan penggunaan system tanam padi sawah diperoleh skor. Untuk menganalisis pengaruh sistem tanam, biaya pemupukan dan biaya pestisida terhadap pendapatan usahatani padi sawah di Kecamatan Birem Bayeun digunakan model analisis regresi linier berganda. Hasil analisis linier berganda diperoleh persamaan regresi linier sebagai berikut:

\section{$Y=-8,28+3,66027 X 1+3,82297 X 2+17,02530 X 3$}

Dengan interprestasi sebagai berikut:

- Koefisien regresi faktor sistem tanam $\left(X_{1}\right)$ sebesar 3,66027. Artinya bila biaya pemupukan dan biaya pestisida dianggap tetap maka setiap penambahan 1 skor sistem tanam akan menyebabkan pendapatan usahatani padi sawah meningkat sebesar Rp. 3.660.270,-/MT.

- Koefisien regresi faktor biaya pemupukan $\left(X_{2}\right)$ sebesar 3,82297. Artinya bila sistem tanam dan biaya pestisida dianggap tetap maka setiap penambahan biaya pemupukan usahatani sebesar 1 juta akan menyebabkan pendapatan usahatani padi sawah meningkat sebesar Rp 3.822.970,-/MT.

- Koefisien regresi faktor biaya pestisida $\left(X_{3}\right)$ sebesar 17,02530. Artinya bila sistem tanam dan biaya pemupukan dianggap tetap, maka setiap penambahan biaya pestisida sebesar 1 juta akan menyebabkan pendapatan usahatani padi sawah meningkat sebesar Rp. 17.025.300,-/MT.

Pengaruh terpisah variabel penerapan sistem tanam, biaya pemupukan dan biaya pestisida terhadap pendapatan usahatani padi sawah di Kecamatan Birem Bayeun diuji dengan menggunakan uji t. Hasil pengujian pengaruh terpisah disajikan pada Tabel 6. berikut:

Tabel 6. Pengujian secara parsial

\begin{tabular}{|c|c|c|c|c|c|}
\hline \multirow{2}{*}{ Variabel } & \multirow{2}{*}{$\mathbf{t}_{\text {hitung }}$} & \multicolumn{2}{|c|}{$\mathbf{t}_{\text {hitung }}$} & \multirow{2}{*}{ Keterangan } & \multirow{2}{*}{ Kesimpulan } \\
\hline & & $5 \%$ & $1 \%$ & & \\
\hline $\begin{array}{l}\text { Sistem } \\
\text { Tanam }\end{array}$ & 1,972 & 2,051 & 2,770 & $\begin{array}{l}t_{\text {hitung }}<t_{\text {tabel }} \\
\text { pada } \alpha=5 \% \\
\text { dan } 1 \%\end{array}$ & $\begin{array}{l}\text { Tidak } \\
\text { berpengaruh } \\
\text { nyata }\end{array}$ \\
\hline $\begin{array}{l}\text { Biaya } \\
\text { Pupuk }\end{array}$ & 2,784 & 2,051 & 2,770 & $\begin{array}{l}t_{\text {hitung }}>t_{\text {tabel }} \\
\text { pada } \alpha=5 \% \\
\text { dan } 1 \%\end{array}$ & $\begin{array}{l}\text { Berpengaruh } \\
\text { nyata }\end{array}$ \\
\hline $\begin{array}{l}\text { Biaya } \\
\text { Pestisida }\end{array}$ & 2,053 & 2,051 & 2,770 & $\begin{array}{l}t_{\text {hitung }}>t_{\text {hitung }} \\
\text { pada } \alpha=5 \% \\
\text { dan } 1 \%\end{array}$ & $\begin{array}{l}\text { Berpengaruh } \\
\text { nyata }\end{array}$ \\
\hline
\end{tabular}

Sumber: Data Primer (2018)

Tabel di atas menunjukkan hasil analisis regresi linier berganda sebagai berikut: 
- Nilai $t_{1}$ sebesar tcari < ttabel 1,972 < 0,05 maka, variabel sistem tanam $\left(\mathrm{X}_{1}\right)$ secara terpisah tidak berpengaruh terhadap pendapatan usahatani padi sawah di Kecamatan Birem Bayeun. Karena petani belum memahami penggunaan sistem tanam yang baik.

- Nilai $t_{2}$ sebesar tcari $>$ ttabel 2,784 $>0,05$ dan 0,01 maka, variabel biaya pemupukan $\left(\mathrm{X}_{2}\right)$ secara terpisah berpengaruh sangat nyata terhadap pendapatan usahatani padi di Kecamatan Birem Bayeun. Karena biaya pupuk yang kurang dapat menghambat produksi padi sawah.

- Nilai $t_{3}$ sebesar tcari < ttabel 2,053 > 0,01 maka, variabel biaya pestisida $\left(X_{3}\right)$ secara terpisah tidak berpengaruh terhadap pendapatan usahatani padi di Kecamatan Birem Bayeun. Karena biaya pestisida yang tinggi maupun rendah tidak mempengaruhi pendapatan usahatani padi sawah.

\section{Kesimpulan}

Rata-rata luas lahan usahatani padi sawah yang dikelola oleh petani adalah sebesar 0,65 hektar. Rata-rata penggunaan tenaga kerja usahatani padi sawah di Kecamatan Birem Bayeun yaitu sebesar 64,31 HKP/MT/UT, rata-rata biaya produksi sebesar Rp. 6.088.167 /MT/UT, rata-rata produksi sebesar $3.220 \mathrm{Kg} / \mathrm{MT} / \mathrm{UT}$, rata-rata nilai produksi sebesar Rp. $14.491 .193,-/$ MT/UT dan rata-rata pendapatan bersih usahatani padi sawah di Kecamatan Birem Bayeun yaitu sebesar Rp. 9.001.833 / MT/UT. Secara parsial (terpisah) variabel sistem tanam tidak berpengaruh, biaya pemupukan berpengaruh sangat nyata dan biaya pestisida tidak berpengaruh terhadap pendapatan usahatani padi sawah di Kecamatan Birem Bayeun Diharapkan petani padi di Kecamatan Birem Bayeun Kabupaten Aceh Timur dalam penggunaan biaya produksi seperti pupuk dan pestisida harus diperhatikan efisiensi penggunaan biaya yang berguna dalam meningkatkan pendapatan/keuntungan usahatani padi sawah. Perlu adanya penyuluhan secara kontinyu kepada para padi di Kecamatan Birem Bayeun Kabupaten Aceh Timur tentang pentingnya budidaya padi secara intensif untuk meningkatkan pendapatan petani.

\section{Daftar Pustaka}

BPP Kabupaten Jombang 2011. Sistem Tanam Benih Langsung. Jombang

BPP Kementrrian Pertanian 2013. Sistem Tanam Legowo. 978-979-540-073-8 Sukamandi.

Domihartini, Rini Sri., dan Amri Jahi. 2005. Hubungan Karakteristik Petani dengan Kompensasi Agribisnis pada Usahatani Sayuran di Kabupaten Kediri, Jawa Timur. Jurnal Penyuluhan Vol.1 No.1. Bogor.

Mubyarto dan Suratno, 1981. Metodelogi Penelitian Ekonomi. Yayasan Agromedika. Yogyakarta

Muhibbin, S. 2002. Psikologi Belajar. PT Raja Grafindo Persada. Jakarta Nazir, Moh, 2005. Metode Penelitian. Cetakan ke V. Ghalia Indonesia, Jakarta. Novizan 2007. Pentujuk Pemupukan Efektif. Agromedia Pustaka, Jakarta Partadireja. 2001. Perhitungan Pendapatan Nasional. Rajawali Press. Jakarta.

Prihatman, 2012. Padi (Oryza sativa L.). Sistim Informasi Manajemen Pembangunan di Perdesaan, Proyek PEMD, BAPPENAS.Jakarta.

Rahim, A. dan Diah R. D. H. 2007. Pengantar Teori, dan Kasus Ekonomika Pertanian. Penebar Swadaya. Jakarta. 
Rini Wudiato 2011. Petunjuk Pengunaan Pestisida. Penebar swadaya , Jakarta .

Soekartawi,2002. Teori Ekonomi Produksi dengan Pokok Bahasan Analisis Fungsi CobbDouglas, Rajawali Pers, Jakarta.

Sudarman, A. 2004. Teori Ekonomi Mikro. BPFE UGM. Yogyakarta.

Sudjana, 2005. Teknik Analisa Regresi dan Korelasi, Tarsio, Bandung.

Sugiyono, 2008. Metode Penelitian Pendidikan (Pendekatan Kuantitatif, Kualitatif dan R E D). Penebar Alfabeta. Bandung

Umar. 2008. Karya Tulis Ilmiah.Gramedia Pustaka Utama. Jakarta

Wiratha. 2006. Metodologi Penelitian Sosial Ekonomi. Andi. Yogyakarta. 